\title{
Taking up Tech Application Inputs to Manage Educational Linguistic Programs
}

\author{
Joel Laffita Rivera \\ Multimedia University, Malaysia
}

\begin{abstract}
The research study explores the range of possibilities that the use of [Microsoft-Word Document Window 10] offers in terms of Language Teaching and Learning, mainly grammar patterns [Adjectives] that can be acquired, treated, and traced through the features of the tech-applications that this Software has made available to the Education Sector. Through a language teaching and learning overview; an elaborated literature framework based on factors and characteristics of tech-application positiveness and educational respects is presented. The research-study was conducted by using a methodological review of researchworks; Internet accredited webpages, language practices classroom, and a compilation of statistics-data from a survey given to Spanish foreign language learners. This study is beneficial to the current demand for groundbreaking tech-innovative foreign language academic practices.
\end{abstract}

Keywords: linguistic, blended learning, behaviorisms, communication, methodology

\section{INTRODUCTION}

As many Educational Institutions are welcoming the benefits of using computer in language teaching and learning classroom; the searching for educational variants that facilitate the process of Second Language Acquisition in the midst of a persistent and progressive revolution of Digital Era continues being a pedagogical necessity to be accomplished. Although language teaching involves knowing the theory of both linguistics and language learning and teaching; we cannot relate to this academic concept without acknowledging the involvement and role of technology in Education. Today, information and communication technologies are probably the most used technologies for foreign language teaching. There is probably no teacher who, next to the standard text books, does not bring authentic materials, like city maps, newspaper articles, book reviews, recipes, poems, etc., to his/her classroom, all of these and even more can be found on the Internet, cited by (Christopher, 2017). (Beetham \& Sharpe, 2013) argue that the use of technologies offers the opportunity to manage the teaching and learning process of a foreign language smoothly. Similarly, other researchers have stepped into the same arena bring out relevant finding when applying computer blended learning academic practices into the process of language teaching and learning (Banados, 2006); (Bijeikiene, Rasinskiene \& Zutkiene, 2011); (Conole, 2006); (Carmen, 2005); (Comas, 2011); (Conole, \& Oliver, 2006); (Hong \& Samimy, 2010); (Joel, 2020); (Lai \& Kritsonis, 2006); (Lopez \& Rodriguez, 2011); (Motteram, 2013). So, updating our language teaching and learning approaches so that they fit into "today tech language classroom educational programs", it is already a must Education principle to follow. (Diana \& Toni, 2011) believe that business educators could benefit not only from identifying 
relevant changes in the global environment at the conceptual and practical level, but also from learning guidelines on how to incorporate these relevant changes in the curriculum.

At present, the need for equipping foreign language teachers with effective linguistic and methodology and technology techniques that could help them appropriately incorporating these disciplines into the language teaching and learning curriculum; it has become an Education predominant-issue to consider. Hypothetically speaking, it might happen a catastrophic incident that paralyzes the use of Internet to sop people using electronic devices with Internet connection. However, if that could be the case, we might still be able to use computer Software programs such as [Microsoft-Word Document Window 10] which does not need Internet connectivity, and through which, we as language teachers can perform blended learning language classroom activities. So, all scholars would agree that setting academic prospects that could potentially benefit the process of Education when necessary, should be welcomed. Moreover, if by doing so, we could be able to use these blended learning academic activities not only to coach university students 'learning, but to help them changing their behavioral study patterns. I do believe that one of the best ways to deal with this specific regard is by incorporating the use of computer tool applications into the process of teaching due to its direct relation with these days' learners learning style. It is not a coincidence that one of the personal-traits that bests describe adult learning is that they prefer to confront challenges rather than accepting that their intellectual capabilities are underestimate. This individuality trait should make academicians pondering about how to take advantages of it to change for good behavioral studies patterns.

Behaviorism, also known as behavioral psychology, is a theory of learning based on the idea that all behaviors are acquired through conditioning, and conditioning occurs through interaction with the environment. Behaviorists believe that our responses to environmental stimuli shape our actions. (Araiba Sho, 2019) argues that even though behaviorists generally accept the important role of heredity in determining behavior, they focus primarily on environmental events. So, based on the fact that behavioral patterns changes are basically subjected to environmental exposures; pragmatically speaking, I would say that the way students these days behave can be accessed through current blended learning teaching approaches.

Based on professional and experimental traditional teaching; I can with confidence say that reasons for which many university students do not perform the way language teachers expect are directly related with behavioral study patterns. However, in this regard, using computer tool applications in the process of language teaching and learning helps to tackle and make right behavioral study patterns, manly when working with university students. Even though the way these students behave could have come from family or society inputs; university students have the intellectual coefficient capability and adult maturity traits to choose for good or bad the way-s to behave according to truthful academic-responsibilities, and this is something of which these learners are very aware of. I therefore think that it will be up to the decision of the makers "academicians and administrative universities bodies" to intelligently embrace and adapt and integrate the current Tech-Environment into Educational Curriculums.

Taking into account the above-remarks, and based on the objective of the research study which is meant to deliver some pedagogical suggestions for using [Microsoft-Word Document Window10] in Spanish foreign language acquisition classroom with emphasis on linguistic gender-usage communication perspectives; the following blended learning referential methodological material is putting forward. See table 1: Spanish Grammar-Microsoft Word Document Assignment, and subsequently Spanish Language Communication Insights: 
TABLE 1

SPANISH GRAMMAR-MICROSOFT WORD DOCUMENT ASSIIGNMENT

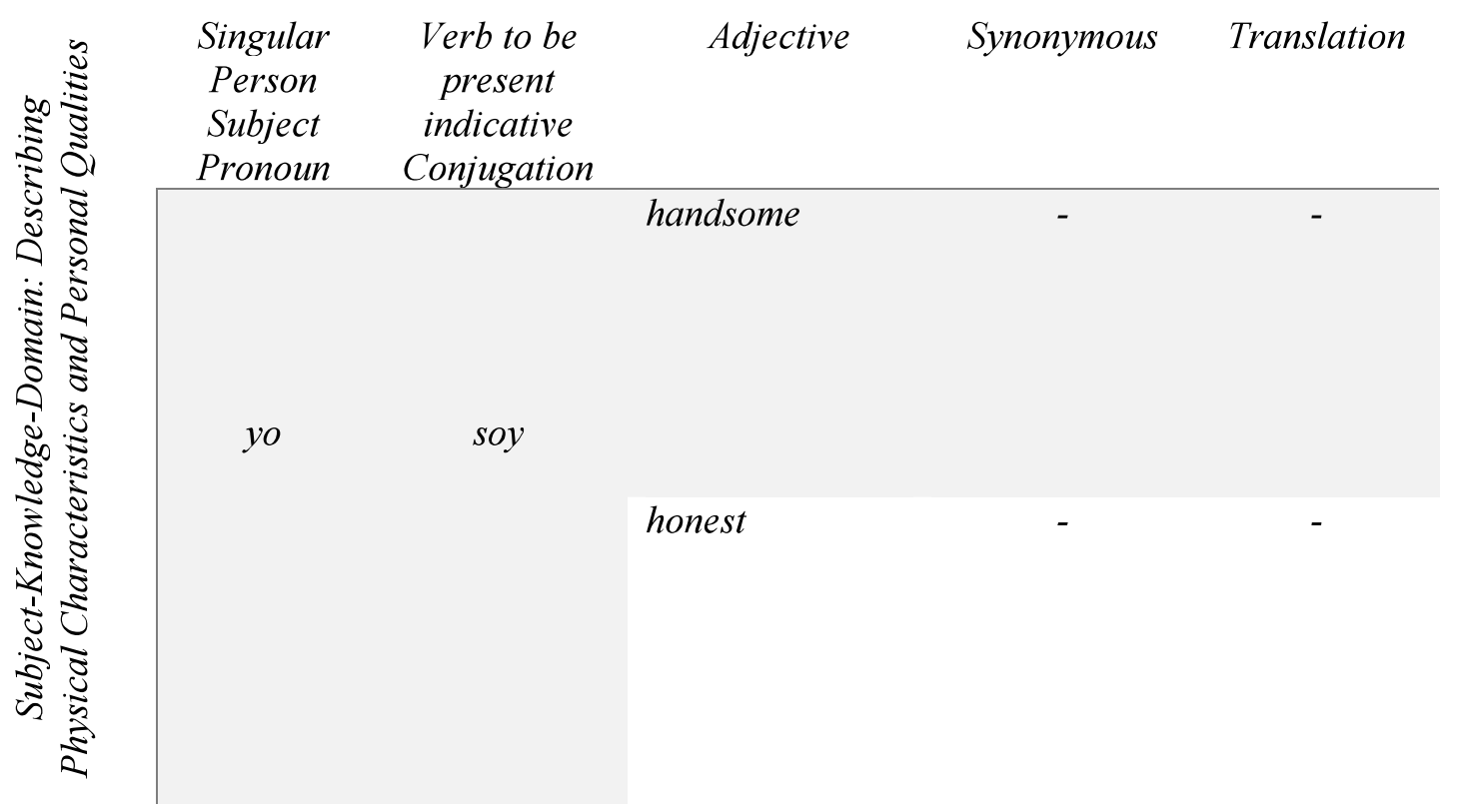

\section{SPANISH LANGUAGE GENDER USAGE COMMUNICATION INSIGHTS}

The fact the use of gender (masculine/feminine) in Spanish Language is a complex linguistic issue to digest, it makes even more comprehensible the realty of being well-instructed when communicating own/or no Physical Characteristics and Personal Qualities in Spanish Language Communication Contexts. Thus, the following Spanish language Applied Linguistics insights are highly recommended:

\section{Writing Communication}

Spanish Language Sentence/Phrase Writing-focused help students further develop their second language acquisition writing skills, and prepare them for the communication demands. It must include the use of Spanish gender grammatical rules. It can be delivered by using the Spanish Grammar-Microsoft Word Document Assignment provided, which is set to allow students exploring and enhancing adjective linguistics traits through the use of [Microsoft-Word Document Window10] features such as [Synonymous and Translate].

\section{Verbal Communication}

Spanish Language Sentence/Phrase Speaking-focused help students further develop their second language acquisition speaking skills. It must be developed within contextual spoken sentences/phrases that have substantial gender-usage communication requirements. See the Grammar Subject-KnowledgeDomain Note in the table 1: Spanish Grammar-Microsoft Word Document Assignment provided.

\section{METHODOLOGY}

Employing principles of research techniques based on the collection of data and its analysis the study began gathering data from specialized materials such as publications focused on the subject being investigated. These materials were analyzed and displaced into the literature-framework exposed in this study. Database from Internet accredited webpages focused on the subject presented were also analyzed and have been displaced under the Heading named Internet Accredited Webpages. As part of the research criterium utilized; academic-insights from a Spanish foreign language classroom were complied. Database 
from a survey given to Spanish foreign language learners were gathered, analyzed, and in accordance displaced. See table 2: Language Course Academic Inputs, and figures from 1-5, Survey Inputs and Outputs.

\section{LANGUAGE COURSE ACADEMIC INPUTS}

\begin{tabular}{rllll}
$\begin{array}{r}\text { Subject Code and } \\
\text { Name }\end{array}$ & $\begin{array}{l}\text { Number of Weeks and } \\
\text { Total Loading Hours }\end{array}$ & $\begin{array}{l}\text { Assignment } \\
\text { Criteria }\end{array}$ & $\begin{array}{l}\text { Students } \\
\text { Number }\end{array}$ & $\begin{array}{l}\text { Computer } \\
\text { Assisted Tool } \\
\text { Applications }\end{array}$ \\
\hline MPU3204 Spanish for & $14 / 43$ & & Mycroft \\
Beginners & & $100 \%$ & - & Document \\
& & Coursework. & Lecture Notes. \\
& & & Edpuzzel. \\
& & & Kahoot. \\
& & Google \\
& & & Classroom. \\
& & & Google Meet.
\end{tabular}

FIGURE 1

\section{SURVEY INPUTS AND OUTPUTS}

Using computer as mediator to study a language subject is adjustable to my preferred tech-environment-living-style

100 responses
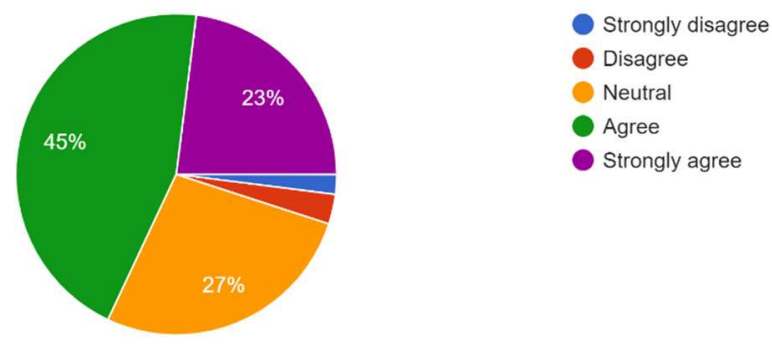

FIGURE 2

SURVEY INPUTS AND OUTPUTS

As a student (a millennium born in the Digital Age) I should be aware of my linguistic-studies responsibilities whether by using computer as mediator for it or not 100 responses

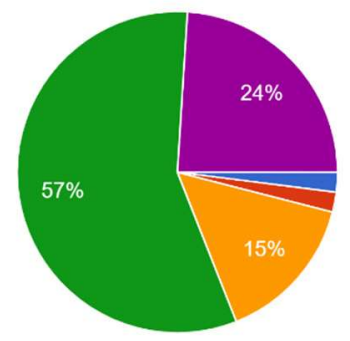

$$
\begin{aligned}
& \text { Strongly disagree } \\
& \text { Disagree } \\
& \text { Neutral } \\
& \text { Agree } \\
& \text { Strongly agree }
\end{aligned}
$$




\section{FIGURE 3 \\ SURVEY INPUTS AND OUTPUTS}

From 1-10 scale raise the level of the Spanish language acquisition you think you have acquired by using computer as mediator

100 responses
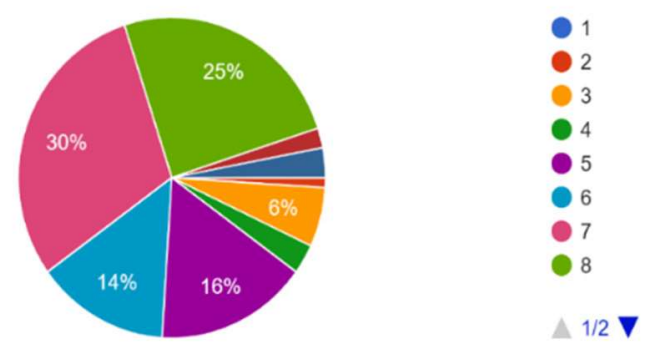

FIGURE 4

SURVEY INPUTS AND OUTPUTS

From 1-10 scale raise the level of the Spanish language teaching by using computer as mediator 100 responses

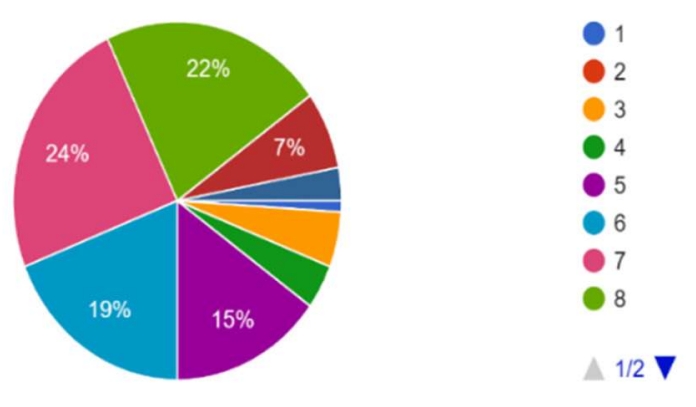

FIGURE 5

\section{SURVEY INPUTS AND OUTPUTS}

From 1-10 scale raise the self-learning beneficial-development-impact you have acquired by using computer as mediator for teaching and learning Spanish language 100 responses
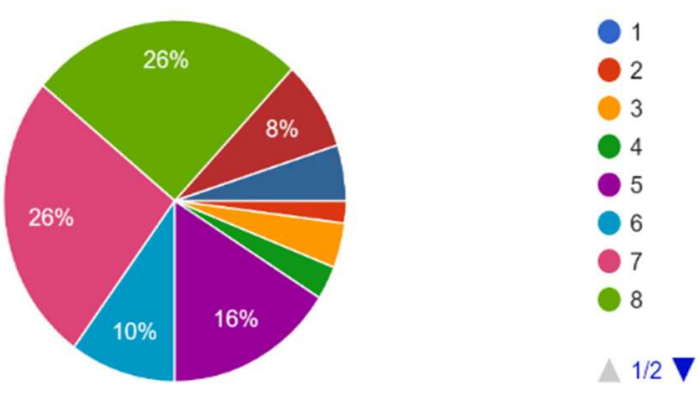


\section{RESULT AND DISCUSSION}

The methodology strategies used in this research study helped to present the facts of the elements accessible in the manuscript, which have been exposed with the purpose to highlight the reasons for which this research study has been conducted, and in this regard offering a rational literature view composed by the main pillars of the research study: 1) Methodology. 2) Subject-Knowledge-Domain. 3) Result and Discussion. Thus, academically speaking I could affirm that the results obtained are valuable. As a point of departure, the study has outlined a series of statements based on the view that other researchers have had on the subject-matter-domain presented, emphasizing that way the important of the role that technology is playing in the field of language teaching and learning. In line with this view, the present research study has related to use of [Microsoft-Word Document Window 10] to explores the range of possibilities that this Software offers in terms of Language Teaching and Learning, mainly grammar patterns [Adjectives] that can be acquired, treated, and traced through the features of the tech-applications made available through it to the Education Sector. Thus, through a language teaching and learning overview; the research study has presented an elaborated literature framework based on factors and characteristics of tech-application positiveness and educational respects, which made possible to add the authentical methodological materials insights provided in this manuscript.

The academic language teaching and learning remarks stated in the manuscript are based on practical teaching and learning classroom when working with Spanish language learners up the beginner's level. These experiences were gathered during a Spanish language program that took place for 14 weeks with 3 credit hrs. each, a language course that is usually delivered by using blended learning approaches. Academically speaking, I would say that using [Microsoft-Word Document Window 10] blended learning designed language assignments it is a viable and efficient Educational Applied Linguistics Prospect to consider. Linguistically and methodologically and technologically speaking, I would say that this prospect could definitely benefit the acquisition, treatment and tracing of Spanish language grammar [Adjectives] that require special tutorial due to the gender-agreement-usage in Spanish Language communication contexts.

The survey given to Spanish language learners served to measure students' level of acceptance and self-learning independency when using computer as mediator in language teaching and learning. The statements were set taking into account students' awareness tech-usage. Statistical analyses have revealed a significant agreement in both metrics. Based on the statements and responses from figures 1 and 2; I could say that the level of [neutral / disagree / strongly disagree] is not really relevant when comparing their outcomes with the level of [agree / strongly agree] shown, and which overpasses the $50 \%$ of approval rate when combining the percentage of these measurements. Based on the scale provided through the survey marked by figures 3, 4 and 5, in which (1-3) represents the low, (4-6) the average, (7-10) the high; I could say that the statistics responses have shown a high level of teaching and learning satisfaction index, and the self-learning beneficial-development-impact that the learners of the Spanish language subject think they acquired when using computer as mediator in the process of the Spanish language teaching and learning, which is a remarkable methodological computer assisted language teaching and learning achievement.

It continues being a realty that incorporating tech-innovative methodological strategies into language teaching and learning educational curriculum programs has become an Education predominant-field to deep exploring in many regards. As the process of digitalization develops so does the process of language teaching and learning, and foreign languages are not excluded. Thus, further research studies should be done to empower the Education Sector by continuing making available blended learning tech-approaches based on Taking up Tec-Application Inputs to Manage Educational Linguistic Programs

\section{CONCLUSION}

In conclusion, one could say that the manuscript presented contains significant literature sources corresponding to the main objective of the research study. The database presented in the manuscript contextualize clearly the subject-matter-domain exposed. In conjunction with which the study has made 
available credential researchers view on the subject discussed and added new supported finding with emphasis on using [Microsoft-Word Document Window 10] to design and conduct blended learning Spanish language assignments, which is not only a viable and efficient Educational Applied Linguistics Prospect to consider, but a recycle-methodological-model to be used for second language acquisition, treatment, and trace. Thus, this study is a valuable contribution to the field of Linguistics and Applied Linguistics and Education, and as such, it lets at the disposition of the readers and the specialized critics for its evaluation.

\section{ACKNOWLEDGEMENT}

The author is very thankful to all the associated personnel in any reference that contributed in/for the purpose of this research. The research holds no conflict of interest and it is not funded through any monetary source other than being sponsored by the professional interest of its author.

\section{REFERENCES}

Aldrey, C.L. (2005). Las nuevas tecnologías y la enseñanza-aprendizaje del español lengua extranjera. In M. Cal, P. Núñez, \& I.M. Palacios, Ignacio M., Nuevas tecnologías en Lingüística (pp. 181-202). Traducción, y Ensenyanza de lenguas (in Spanish).

Araiba, S. (2019, June). Current diversification of behaviorism. Perspectives on Behavior Science, 43(1), 157-175. doi:10.1007/s40614-019-00207-0. PMC 7198672. PMID 32440649.

Banados, E. (2006). A blended learning pedagogical model for teaching and learning EFL successfully through an online interactive multimedia environment. CALICO Journal, 23(3), 533-550.

Beetham, H., \& Sharpe, R. (Eds.). (2013). Rethinking pedagogy for a digital age: Designing for 21 st century learning. Routledge.

Bijeikiene, V., Rasinskiene, S., \& Zutkiene, L. (2011). Teachers' attitudes towards the use of blended learning in general English classroom. Studies about languages, (18), 122-127. doi:10.5755/j01.sal.0.18.420

Brooks, C., \& Pomerants, J. (2017). ECAR Study of Undergraduate Students and Information Technology.

Comas-Quinn, A. (2011). Learning to teach online or learning to become an online teacher: An exploration of teachers' experiences in a blended learning course. ReCALL, 23(3), 218-232. doi: $10.1017 / \mathrm{s} 0958344011000152$

Conole, G., \& Oliver, M. (Eds.). (2006). Contemporary Perspectives in E-learning Research: Themes, Methods and Impact on Practice. London: Routledge.

Hong, K.H., \& Samimy, K.K. (2010). The influence of L2 teachers' use of CALL modes on language learners' reactions to blended learning. Calico Journal, 27(2), 328-348. doi:10.11139/cj.27.2.328348

Joel, L. (2020). Based Conceptual Blended Learning Didactic Prospect. doi:10.47191/ijsshr/v3-i11-13

Lai, C., \& Kritsonis, W. (2006). The advantages and disadvantages of computer technology in second language acquisition. National Journal for Publishing and Mentoring Doctoral Student Research, $3(1), 1-6$.

Lopez-Perez, M.V., Perez-Lopez, M.C., \& Rodriguez-Ariza, L. (2011). Blended learning in higher education: Students' perceptions and their relation to outcomes. Computers and Education, 56(3), 818-826.

Motteram, G. (2013). Developing and extending our understanding of language learning and technology. 


\section{ACREDITED INTERNET WEBPAGES}

https://en.wikipedia.org/wiki/Blended_learning

https://theconversation.com/how-technology-is-changing-language-and-the-way-we-think-about-theworld-35856

https://www.microsoft.com/en-my/windows

https://www.mindflash.com/elearning/what-is-blended-learning

https://www.youtube.com/watch?v=fbQ2Qf4vMeQ 